\section{Endoscopic closure of esophageal fistula using a novel "clips and loop" method}

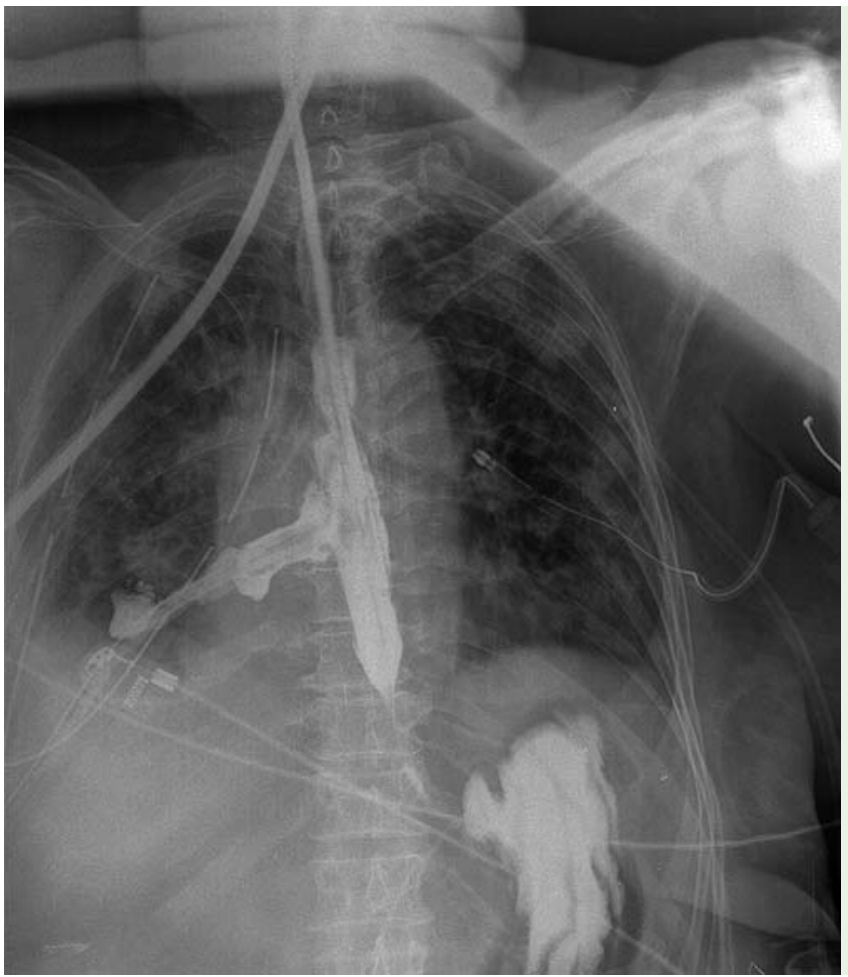

Fig. 1 Esophagography with a watersoluble contrast agent shows an esophagomediastinal fistula.

Fistula can develop rarely between the esophageal lumen and other mediastinal structures. The majority of cases are caused by malignancy. Benign causes include infections, other inflammatory conditions, postsurgical trauma, and prolonged periods of endotracheal intubation or tracheostomy tube placement. In most cases of fistula, surgery is required. There are, however, a number of reports

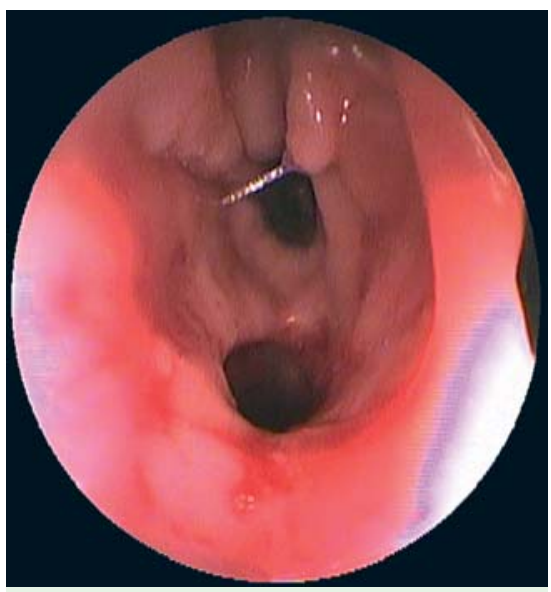

Fig. 2 Opening of the fistula. in the literature of endoscopic methods of attempting fistula closure: the application of fibrin glue, use of covered esophageal stents, and clipping have been described, for closure of esophagotracheal, bronchoesophageal, and esophagopleural fistulas [1-4].

We report the case of a patient who developed an esophagomediastinalbronchial fistula ( $\bullet$ Fig. 1 ) after a pulmonary resection (sleeve lobectomy).

An external mediastinal drain was inserted, and esophagogastroduodenoscopy (EGD) promptly identified a large fistula opening of $25 \mathrm{~mm}$ in diameter in the middle part of the esophagus ( $\bullet$ Fig. 2 ).

Another EGD was done 2 days later, with attempted closure of the fistula by clipping. However placement of the clips using the traditional method was very difficult, because the edges of the fistula were fibrotic and because of the large diameter of the opening. For these reasons, five clips (Resolution; Microvasive, Boston Scientific, Natick, Massachusetts, USA) were positioned at the edges of the opening ( Fig. 3 ) and an endoloop (Olympus, Tokyo, Japan) was looped and

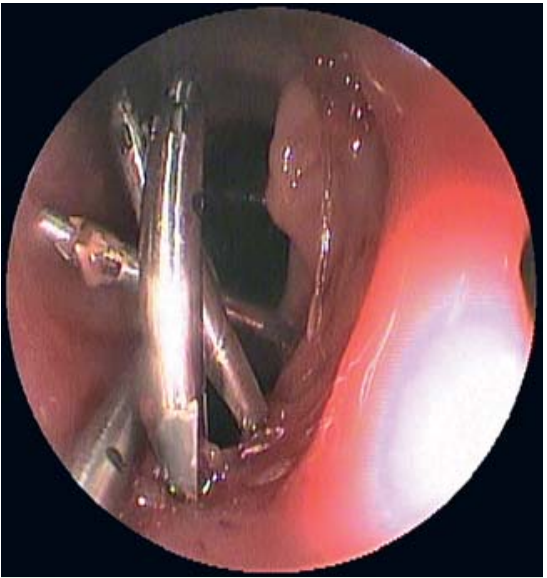

Fig. 3 Clips positioned at the edges of the fistula opening.

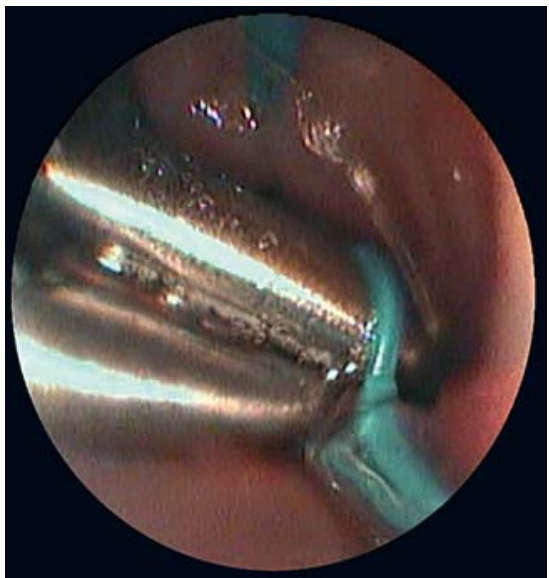

Fig. 4 Endoloop attached to the heads of the clips.

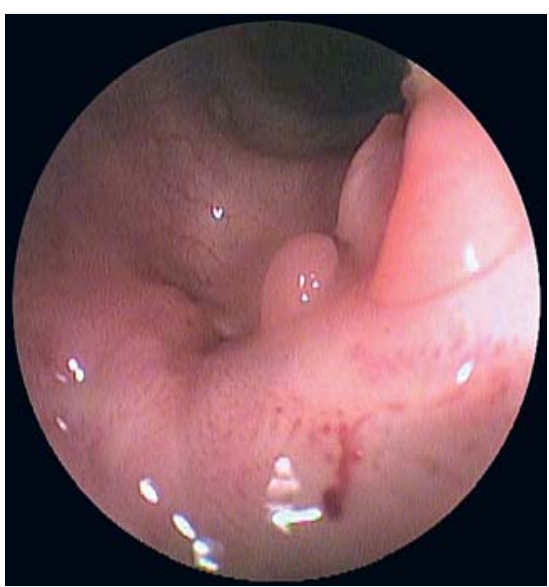

Fig. 5 Endoscopic view showing complete healing of the fistula. 
tightened round the heads of the clips in order to close the opening ( $\bullet$ Fig. 4). Another EGD performed 1 month later revealed complete healing of the fistula with formation of scar tissue ( $\bullet$ Fig. 5 ). To the best of our knowledge, this is the first report of an endoscopic approach that combined clips and endoloop to treat a fistula. Because of the limited width of an open clip, it is difficult or impossible to close a large mucosal defect, so we believe that in such situations the technique described could be a useful procedure when traditional clip application fails.

Endoscopy_UCTN_Code_TTT_1AO_2AI

\section{Luigiano, F. Ferrara, A. M. Polifemo, C. Fabbri, S. Ghersi, M. Bassi, N. D'Imperio}

Unit of Gastroenterology and Digestive Endoscopy, AUSL Bologna, Bellaria-

Maggiore Hospital, Bologna, Italy

\section{References}

1 Ogunmola N, Wylie R, McDowell K et al. Endoscopic closure of esophagobronchial fistula with fibrin glue. J Pediatr Gastroenterol Nutr 2004; 38: 539-541

2 Chauhan SS, Long JD. Management of tracheoesophageal fistulas in adults. Curr Treat Options Gastroenterol 2004; 7: 31 -40

3 Mizobuchi S, Kuge K, Maeda H et al. Endoscopic clip application for closure of an esophagomediastinaltracheal fistula after surgery for esophageal cancer. Gastrointest Endosc 2003; 57: 962 - 965

4 Murdock A, Moorehead RJ, Tham TC. Closure of a benign bronchoesophageal fistula with endoscopic clips. Gastrointest Endosc 2005; 62: $635-638$

\section{Bibliography}

DOI 10.1055/s-0029-1214430

Endoscopy 2009; 41: E249-E250

(c) Georg Thieme Verlag KG Stuttgart · New York . ISSN 0013-726X

\section{Corresponding author}

\section{Luigiano, MD}

Unit of Gastroenterology and Digestive Endoscopy AUSL Bologna Bellaria-Maggiore Hospital

Largo Nigrisoli 2

40133 Bologna

Italy

Fax: +39-51-6478967

carmeluigiano@libero.it 